ISSN 1517-7076 editorial, 2012

\title{
Editorial
}

\section{Materials and Environment}

During so many years our society purloined nature's components without worrying with the environmental impact this would cause, or with the useful reuse of residues from such materials. But the behavior based on the belief that nature would be inexhaustible and that our planet would support any type of aggression is no longer well accepted. This has changed the way engineering companies act and has induced the dawning of new research lines in the area of materials. As a result, the journal Materia receives articles that explore the recycling and the substitution of materials with financial and environmental advantages. This perspective is well revealed in the present number of the journal. In one case, the possibility to use catalysts waste used in petroleum refining to coat plain carbon steel was demonstrated. Such steel acquires better tribological properties and is then fitted for use in applications requiring resistance to thermal shock. This adds value to a conventional and cheap steel that is produced in large scale. In another case, wastes from the ornamental rock industry are shown to be adequate to be used as alternative raw material, also acting as a melting agent, in the fabrication of high-quality aluminum-based porcelains for electrical applications. Still in the area of ceramic materials, the possibility to add finely ground roof tile chamotte in the basic mass typically used in the production of semi-porous tiles is evaluated.

There are about 600 million automobiles nowadays in the world using and dumping an enormous amount of tires. This has become a big environmental problem. There are several alternatives researched to mitigate such a problem. One solution presented in this number of the journal is to incorporate the tires' rubber waste in thermo-rigid polymeric matrix composites. It was verified that incorporating up to $25 \%$ of rubber wastes qualifies the composite for engineering applications. On the other hand, it is also very useful to evaluate the possible substitutes for the use of heavy metals and chemical components that poison the environment and are toxic for the living beings. That's why a study is presented on the performance of layers that use rare earth elements in substitution to the use of hexavalent chromium in corrosion protection coatings for steels.

In addition to reutilize residues and to substitute deleterious elements, another practice that is very useful and interesting for the materials area with strong environmental interest is to make viable the sustainable use of forest and rural resources. The main requirement for that is to make precise and trustable characterization of such materials. Two such examples are offered in the present journal number. One deals with the guadua angustifolia-Kunth, a type of a bamboo, which is able to substitute wood with advantages, that had its hardness properties and thermophysic parameters characterized. The other one evaluates the use of electron beam irradiation of lignocellulosic fibers extracted from the petiole of the buriti palm tree, as a way to improve their mechanical strength and to qualify them to be used to reinforce polymeric composites.

If you have developments in this interface area between materials and environment your articles will be very much welcomed for publication in the journal Materia.

Cordially,

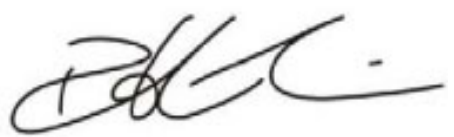

Paulo Emílio V. de Miranda

Editor-in-Chief

Materia Journal 